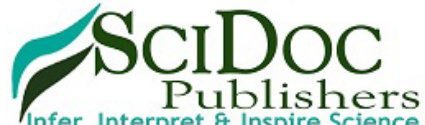

\author{
International Journal of Dentistry and Oral Science (IJDOS) \\ ISSN: 2377-8075
}

\title{
The Efficacy Of Adhesive Tissue Iceberg-Gluein Reducing Post-Operative Bleeding And Pain After Surgical Removal Of Impacted Lower Third Molars: A Randomized Clinical Trial
}

Mohammed Shukur ${ }^{1}$, Omar Heshmeh², Safaa Shihabi ${ }^{3 *}$

${ }^{1}$ Msc student in Department of Oral \& Maxillofacial Surgery, Faculty of Dentistry, Damascus University, Syria.

${ }^{2}$ Professor in Department of Oral \& Maxillofacial Surgery, Faculty of Dentistry, Damascus University, Syria.

${ }^{3}$ MSc in Pediatric Dentistry, Faculty of Dentistry, Damascus University, Syria.

\section{Abstract}

Background: There is various wound closure techniques have been used in medical literatures like traditional non-absorbable sutures and advanced modalities, suchas synthetic absorbable sutures, surgical staples and tissue adhesives. Suturing has been the conventional method for approximating wound margins. However,suturing has many disadvantages leading to various alternative material closure options.

This need to an interest in tissue adhesives such as new generation of cyanoacrylate which has unique properties lead us to focus on this technique in our study.

Aim: Evaluation the efficacy of the adhesive tissue(iceberg-glue) in minimizing the post-operative bleeding and pain after surgical removal of impacted lower third molars.

Materials and Methods: Sample size consisted of 19 patients with bilateral and symmetrical impacted lowers third molars were included in this randomized, split-mouth study.

Patients with any pre-existing pathology or systemic disease were excluded.

On one random side were surgically closure using silk suture (3-0) (group A), and using an adhesive tissue on the contralateral side (groupB). The comparison of the post-operative bleedingevaluation rated from (3hours, 6hours, 9hours, 12hours) post surgically, and post-operative pain evaluation in (one, third, and seven days) post surgically, the bleeding and pain assessment according to VAS scales.

Result: Bleeding assessment according to Mann-Whitney U test,the outcome reveals statistically significant differences for adhesive group in the ( 3 hours, 6 hours, 9 hours) after surgery in adhesive tissue group $(p<0.05)$ where as there is no significant difference in (12 hours) after surgery between two groups ( $p>0.05)$, pain assessed according to T-student test which reveals statistical significant differences in the one and third days post surgically for adhesive group and there is no differences in the seven days between the two groups.

Conclusion: The iceberg-gluehas a significant and effective effect on hemostasis after surgical extraction of impacted lower molars compared with traditional suture with 3-0 silk thread.

Keywords: Surgical Extraction; Adhesive Tissue; Suture-Impacted Third Molar; Bleeding; Pain.

\section{Introduction}

Third molars are the most susceptible to impaction because they are the last teeth to erupt, so they do not find enough space to erupt [1]. Extraction of impacted third molars is the most common surgical procedure in the dental clinic (Brad and Jafoo) often characterized by the following period. Surgical extraction of third molars in the presence of edema, hemorrhage and pain [2] Although suturing is the common traditional method for rounding wound edges in impacted molars, it has many disadvantages as it can cause a permanent effect of the sutures, Swelling in the wound and injury as a result of needle insertion in addition to reactions due to the presence of a foreign body, the formation of granules and isolates in tissues and infection [3]. Various alterna-

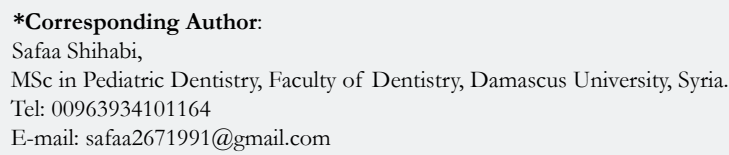

Citation: Mohammed Shukur, Omar Heshmeh, Safaa Shihabi. The Efficacy Of Adhesive Tissue Iceberg-Gluein Reducing Post-Operative Bleeding And Pain After Surgical Removal Of Impacted Lower Third Molars: A Randomized Clinical Trial. Int J Dentistry Oral Sci. 2021;8(10):4806-4811. doi: http://dx.doi.org/10.19070/2377-8075-21000974

Copyright: Safaa Shihabi 2021 . This is an open-access article distributed under the terms of the Creative Commons Attribution License, which permits unrestricted use, distribution and reproduction in any medium, provided the original author and source are credited. 
tive materials have been used to close the edges of the wound since ancient times, as well as from human hair to surgical silk threads Although the materials of modern surgical sutures and the techniques used are very accurate and studied, the desired goal of closing the wound and reducing bleeding may remain unrealized (Kumar et al., 2013), so there is a need for alternative closure methods. This need leads to attention in surgical plasters of cyanoacrylate as an alternative to surgical sutures in order to close these wounds, whose adhesive properties were first described in 1959 and presented to the Food and Drug Administration in 1964 [4].

However, the use of ethyl and methyl cyanoacrylate has been abandoned due to its toxicity to tissues and the cause of a clear reaction against a foreign body [5], but newer generations of cyanoacrylate such as n-butyl-2 cyanoacrylate.octyl- 2 cyanoacrylate and isiamyl 2- cyanoacrylatel -n-butyl 2 cyanoacrylate+oca 2-octyl cyanoacrylate.

Which is characterized by the length of the chain and therefore the strength of toxicity and adhesion decreases, flexibility and polymerization time increase and become more bioacceptable [6].

In addition to its immediate hemostatic, ease ofapplication and bacteriostatic properties, it is a good choice for closing surgical incisions. One of the latest cyanoacrylate products is Iceberg-Glue, which was manufactured in Italy several years ago and was put up for internal use and has the CE mark. It differs from previous products in being a comonomer rather than a simple monomer. Iceberg Glue is composed of two monomers, n-butyl 2 cyanoacrylate + oca 2 - octylcyanoacrylate. This monomer is manufactured by the company. The addition of OCA contributes to the thermo-diffusive polymerization of up to 45 degrees and also helps to accelerate the polymerization process and reduce histotoxicity [7], the use of Iceberg-GlueIt offers an additional benefit in hemostasis of bleeding surfaces due to its coagulant action, as it can be used as a dressing after dental extractions [8] and it can also be used as a topical hemostatic after intraoral surgeries in patients with hemorrhagic diseases [9]. Where cyanoacrylate has been used in maxillofacial surgery [10] and oral surgery [11], such as closing the incision after climax surgery [12] as well as closing granular fistulas [13].

Setiya et al [14] et al. evaluated the advantages and disadvantages of cyanoacrylate tissue adhesive after surgical extraction in sutureless wound closure after surgical extraction of impacted lower molars and found statistical significance in reducing pain, bleeding and edema compared with the use of surgical suture In any case, the healing was the same in both cases.

Setiya et al [14] et al. evaluated the advantages and disadvantages of cyanoacrylate tissue adhesive after surgical extraction in sutureless wound closure after surgical extraction of impacted lower molars and found statistical significance in reducing pain, bleeding and edema compared with the use of surgical suture However, the recovery was the same in both cases.

Waite and cherala 2006 [15] have good results and fewer complications after surgery of the lower third molars without sutures, with less pain and faster recovery.

\section{Materials And Methods}

The sample consisted of 38 cases of surgical extraction of impacted lower third molars in 19 patients from the Department of Oral and Maxillofacial Surgery at the University of Damascus, where the extraction was performed for each side separately with an interval of two weeks. The first group (the control group)figure [4], where the surgical extraction was performed, after which the wound was closed by traditional suturing with silk thread 30/ (figure2), The second group (study group) figure [5], where the surgical extraction was performed and after that the wound was closed with the Iceberg-Glue tissue adhesive.(figure1)

The place where the extraction will take place, the wound will be closed with the adhesive tape, and the place to be started was chosen randomly. Patients were also selected from the auditors of the Department of Oral and Maxillofacial Surgery at the Faculty of Dentistry at Damascus University. The inclusion creteria were: The presence of impacted lower third molars with medial embolism of medium depth, The patient does not suffer from any general diseases, The patient's age is between 19-30 years, Patients are neither smokers nor alcoholic, Non-pregnant women, finally the Patients who wanted to extract the lower third molars and who met the study criteria were accepted.

\section{Preoperative stage}

After questioning the patient and making sure that he agrees with the conditions of the research sample, the party to be started is chosen, as well as the method used in the extraction, by lottery using a coin.

\section{Radiographic evaluation}

Panoramic photo before surgery. (figure3)

\section{Postoperative stage}

The surgical work was performed on the right and left sides using the same surgical technique and by the same surgeon with an interval of two weeks. The difference was in the method of closing the incision after extraction, where the incision was closed in the control group by suturing with 3.0 silk thread, while the incision was closed in the study group. By gluing a cyanoacrylate IcebergGlue adhesive.

\section{Surgical methods in group A}

After performing Regional anesthesia of the inferior alveolar nerve (IAN) and the buccal nerve, using $2 \%$ lidocaine solution with adrenaline at a concentration of $1 / 80000$. A crestal incision was made with one vertical incision in the lateral of second molar and full-thickness mucoperiosteal flap was raised to gain access to the bone. After adequate bone removal, the tooth was removed by appropriate elevators. The flap was repositioned and closed with 3-0 silk, and the sutures were removed after 7 days.

\section{Surgical methods in group B}

After performing Regional anesthesia of the inferior alveolar 
nerve (IAN) and the buccal nerve, using 2\% lidocaine solution with adrenaline at a concentration of $1 / 80000$, a crestal incision was made with one vertical incision in the lateral of second molar and full-thickness mucoperiosteal flap was raised to gain access to the bone. After adequate bone removal, the tooth was removed by appropriate elevators. The flap was repositioned and closed with iceberg-glue.

\section{Postoperative recommendations}

- The drug prescription was standardized for all patients, where the patient is given an antibiotic augmentin $1 \mathrm{~g}$ twice daily for five days, in addition to flam-k three times a day after food when necessary.

- applying ice packs for 10 minutes and removing them for 10 minutes in the first six hours, avoiding pulling the cheek or placing the tongue on the wound, using soft food in the first three days of the operation, mouth rinses for two weeks, and the review After two weeks.

\section{Postoperative stage}

Patients in both groups were followed in the same way, as follows:

\section{1-Bleeding evaluation:}

The degree of bleeding was monitored within 12 hours after surgery by means of the VAS visual analog scale in four different time periods ( 3 hours, 6 hours, 9 hours, and 12 hours after surgery) before the operation. The patient, as this indicator consists of four degrees, giving the numbers -4-3-2-1-0:

\section{2- Pain evaluation:}

The degree of postoperative pain was monitored by means of the visual indicator VAS (figure 6) in three different time periods (the first day, the third day, the seventh day) of the operation by the patient, as this indicator consisted of 10 degrees giving numbers from 0 to10.

Figure 1. Iceberg-Glue tissue adhesive packaging.
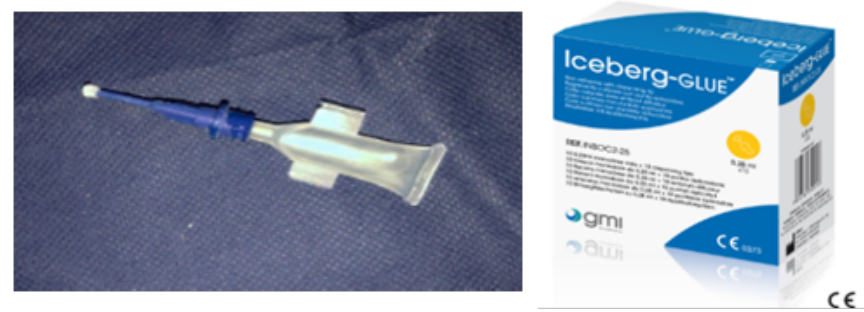

Figure 2. The thread used.

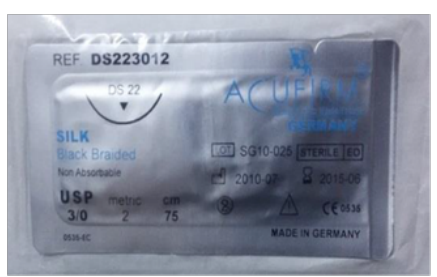

Figure 3. Panoramic Photo.

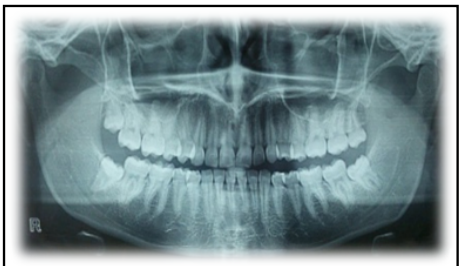

Figure 4. Method of group (A).

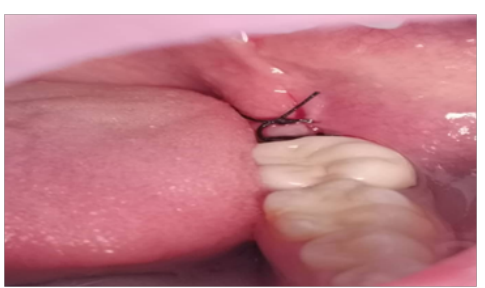

Figure 5. Method of group (B).

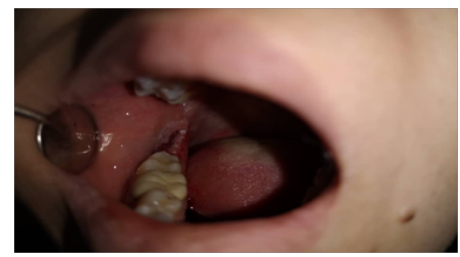




\section{Results}

Studying the degree of bleeding according to the time period studied:

\section{Mann-Whitney U Test results:}

P-value is smaller than the value 0.05 after three hours, after six hours, and after nine hours, thatis, at the $95 \%$ confidence level, there are statistically significant differences in the frequency of the degree of bleeding after three hours, after six hours and after nine hours between the group A and the group Bin the researchsample. the degree of bleeding after three hours, after six hours, and after nine hours in the group B was lower than in the group A.

After twelve hours, P-value was much greater than the value 0.05 , that is, at the $95 \%$ confidence level, there were no statistically significant differences in the frequency of the degree of bleeding after twelve hours between the two groups.
Studying the effect of the method of closing the intra-oral incision on the amount of pain visually according to the studied period of time:

P- Value is much smaller than the value 0.05 on the first day and the second day, that is, at the $95 \%$ confidence level, there are statistically significant differences in the average values of the amount of visual pain on the first day and on the third day between the two groups. We conclude that the values of the amount of pain visually on the first day and on the third day in the group B was smaller than in the group A. On the seventh day, P-Value was greater than the value 0.05 , that is, at the $95 \%$ confidence level, there were no statistically significant differences in the average values of the amount of visual pain on the seventh day between the two groups.

\section{Discussion}

N-butyl-2-cyanoacrylate is a biocompatible tissue adhesive that

Figure 6. Visual Indicator of Pain.

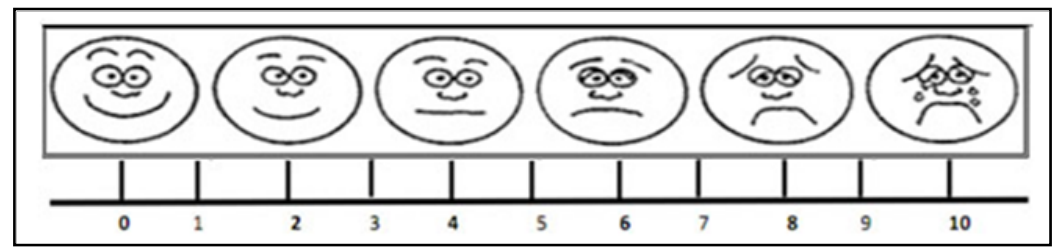

Table 1. The visual indicator of hemorrhage.

\begin{tabular}{|l|c|c|}
\hline 0 & Nob leeding & The patient does not detect any blood in the saliva \\
\hline 1 & Blood seeping & The patient detects slight blood, but it is not worthwhile \\
\hline 2 & Temporery little bleeding & The patient has a little bleeding sometimes \\
\hline 3 & Continuous little bleeding & The patient has little bleeding most of the time \\
\hline 4 & Heavy bleeding & Continuous heavy bleeding \\
\hline
\end{tabular}

Table 2. Shows the results of the Mann-Whitney $U$ test to study the significance of the differences in the frequency of the degree of bleeding between the group of intraoral incision closure using Iceberg-Glue tissue tape and the group of incision closure of intraoral incision using traditional suture in the research sample, according to the time period studied.

\begin{tabular}{|c|c|c|c|}
\hline \multicolumn{4}{|c|}{ The studied variable =degree of bleeding } \\
\hline The time period studied & Value for U Mann-Whitney & P-Value & The significance of differences \\
\hline After 3 hours & 98.5 & 0.010 & There are significantdifferences \\
\hline After 6 hours & 49.5 & 0 & There are significantdifferences \\
\hline After 9 hours & 92.5 & 0.003 & There are significantdifferences \\
\hline After 12 hours & 161.5 & 0.152 & No significant differences \\
\hline
\end{tabular}

Table 3. Shows the results of the Student's T-test for independent samples to study the significance of differences in the average values of visual pain between the group of intraoral incision closure using Iceberg-Glue and the group of intraoral incision closure with conventional suture in the research sample, according to the time period thoughtful.

\begin{tabular}{|c|c|c|c|c|}
\hline \multicolumn{5}{|c|}{ The studied variable = values of visual pain } \\
\hline $\begin{array}{c}\text { The time period } \\
\text { studied }\end{array}$ & $\begin{array}{c}\text { The difference between } \\
\text { the two averages }\end{array}$ & Value-t & P-Value & The significance of differences \\
\hline First day & -0.79 & -3.763 & 0.001 & There are significantdifferences \\
\hline Third days & -0.63 & -3.233 & 0.003 & There are significantdifferences \\
\hline Seven days & -0.32 & -2 & 0.053 & No significant differences \\
\hline
\end{tabular}


has favorable properties, such as fine flow and rapid hardening, and has strong bonding properties and strength to hold the edges of the tissue together. The valence bond and van der Waals force help achieve tissue adhesion. After n-butyl-2-cyanoacrylate is applied, it forms a strong bond through the polymerization reaction with exothermic water, tissue moisture or blood. Cyanoacrylate is exothermic substances released through the polymerization reaction and they are also bacteriostatic. The wound site closed with nbutyl-2-cyanoacrylate showed less postoperative pain than those closed by other methods finally, cyanoacrylates are good hemostatic agents [3]. One of the hypotheses states that the formation of a micro-layer through the organic salt ester due to mechanical blockade, which slows the blood flow and provides a surfactant to stimulate the coagulation cascade. Evidence has shown that the nano-layer forms a porous mass which is invaded by the blood and thus there will be subsequent clotting through the pores of the adhesive [5]. Cyanoacrylate offers various advantages such as fast and effective hemostasis, ease of application, bactericidal properties, and fast tissue adhesion. Tough and soft, maximum bonding strength and waterproof housing. They also have a wide range of applications such as: organ repair, vessels, mucosal graftDermatology: Closing lacerations and fissures: Treating wounds after extractions: Repairing mandibular fractures [5].

In order to maximize the adhesion and minimize patient discomfort, surgeons and physicians have suggested the use of tissue tapes as an alternative to sutures for closing wounds. Ice-berg glue is one of the most commonly used tissue tapes. Several gelatin derivatives have been investigated for their use as tissue adhesives in surgery, such as epoxide, polyurethane, and resorcin. Iceberggluehas gained wider acceptability and has achieved better results than gelatin. In the past 50 years, polymeric adhesives have been used in medical and dental practices. One of the drawbacks of polymers is that they are incompatible with tissues and can produce a severe inflammatory reaction [5] by the early 1970s; cyanoacrylate gum was used to repair bones. In the 1996 Vietnam War, cyanoacrylate was used as a hemostatic agent for wounded soldiers. Adhesives such as iceberg-gluenot only require less time to close the wound compared to that required by traditional methods, but also reduce the spread of infection and improve the aesthetics.

Since iceberg-glueglue has superior properties compared to those of other cyanoacrylates, it may be better for wound healing and therefore we believe that there is a need for clinical evaluation of its role in intraoral wound closure.

We agreed with the study of Setiya et al with regard to the bleeding index, where they studied the evaluation of phagocytosis, the advantages and disadvantages of cyanoacrylate tissue adhesive, through wound closure after surgical extraction of the impacted lower molars. They were studied on 50 patients with impacted lower molars. The statistical analysis showed that the use of $\mathrm{Cy}-$ anoacrylate wound closure tape causes less pain after surgery, as well as bleeding and swelling compared to the use of sutures, and therefore there was better hemostasis than the control side, but the healing was the same in both groups [14].

We also agreed with the study of those who obtained good results, better hemostasis and fewer complications after surgical extraction of impacted lower molars in the study side in which surgical tape was used compared with the control side in which surgical sutures were used [15].

We also agreed with the study of Surindar et al, who obtained effective and statistically significant results regarding hemostasis index after minor intraoral surgeries and proved that cyanoacrylate adhesive acts on instant polymerization upon adhesion with these oral tissues [20].

In the same way, Kulkarni et al noted the use of cyanoacrylate after periodontal surgery [3].

We also agreed with the study of Milton et al, who observed that there is immediate hemostasis during treatment of the bleeding pulp [16].

We also agreed with fuad and maged study, they concluded the hemostatic effect of cyanoacrylate in warfarin-treated patients who underwent oral surgery [9].

We also agreed with the study of ghoreishian et al that showed that the hemostatic effect of cyanoacrylate was significantly better compared to conventional suture on the first and second day after surgery [18].

The same result was noted by ajit et al [15].

Also in our study, significant and significant results were obtained for the advantage of iceberg glue in hemostasis compared to the suture side, where it was found that the degree of bleeding after 3 hours, 6 hours, 9 hours was lower than in the tissue adhesive group where $(\mathrm{p}=0.0104 ; \mathrm{p}=0.000 ; \mathrm{p}=0.003)$, respectively, where $\mathrm{p}$-value $<0.05$, while there were no significant differences after 12 hours, where $(p=0.152)$, and $p$-value $>0.05$ compared with the tailoring party.

Also in our study, we obtained significant and noticeable results for the preference of iceberg glue in the intensity of pain compared to the suture side. $<0.05$ while there was no significant difference on the seventh $\mathrm{d} 9$ ay $(\mathrm{p}=0.053)$ and $\mathrm{p}$-value $>0.05$ compared with the suture side.

Regarding the pain metric, we agree with the researcher's pasqualini and cocero [2] who found that the pain was less severe with secondary healing than with primary healing after surgical extraction of impacted molars.

The same applies to the study of the researcher Ellis [17]) who noticed that the pain was less in the tissue adhesive group than in the suture group, in contrast to the result obtained by the researcher Ghoreishian et al [18] which there were no fundamental differences pain between the two groups in his study.

Researcher kulkarni [3] found that the pain was less after using tissue adhesives after periodontal surgeries.

Researcher Boaz et al [19] concluded that tissue adhesive causes less pain than suture, while researcher Ajit et al [14] saw significant differences in pain intensity in both groups after three days of surgery, and this is what it may return due to the lack of tissue infections after this period.

Also in the study snehasetiya et al [14] saw a significant decrease 
in pain intensity on the first, second and third postoperative days in favor of the tissue adhesive group.

\section{Conclusion}

Iceberg glue has a significant and effective effect on hemostasis and pain after surgical extraction of impacted lower molars compared with traditional suture with $3 / 0$ silk thread.

\section{Acknowledgment}

This research was funded by Damascus University.

\section{References}

[1]. Hupp JR, Tucker MR, Ellis E. Contemporary oral and maxillofacial surgery.2008.

[2]. Pasqualini D, Cocero N, Castella A, Mela L, Bracco P. Primary and secondary closure of the surgical wound after removal of impacted mandibular third molars: a comparative study. Int J Oral Maxillofac Surg. 2005 Jan 1;34(1):52-7.

[3]. Kulkarni S, Dodwad V, Chava V. Healing of periodontal flaps when closed with silk sutures and N-butyl cyanoacrylate: a clinical and histological study. Indian J Dent Res. 2007 Apr-Jun;18(2):72-7.Pubmed PMID: 17502712.

[4]. Saltz, R. and D.M. Toriumi.Tissue glues in cosmetic surgery.CRC PressI Llc. 2004.

[5]. Kumar VR, Rai AB, Priyayadav. Comparative evaluation of n-butyl cyanoacrylate and silk sutures in intra oral wound closure-A clinical study. J. Adv. Oral Res. 2010 Oct;1(1):37-42.

[6]. Leggat PA, Smith DR, Kedjarune U. Surgical applications of cyanoacrylate adhesives: a review of toxicity. ANZ J. Surg. 2007 Apr;77(4):209-13.

[7]. Leonardi M, Barbara C, Simonetti L, Giardino R, Aldini NN, Fini M, et al. Glubran 2: a new acrylic glue for neuroradiological endovascular use. Experimental study on animals. Interv Neuroradiol. 2002 Sep 30;8(3):245-50. Pubmed PMID: 20594482.

[8]. Dogon IL, Heeley JD. A study on the use of fluoroalkyl cyanoacrylate adhe- sive as a hemostatic agent and dressing after exodontia. Oral Surg Oral Med Oral Pathol. 1978 Apr;45(4):503-15.Pubmed PMID: 417279.

[9]. Al-Belasy FA, Amer MZ. Hemostatic effect of n-butyl-2-cyanoacrylate (histoacryl) glue in warfarin-treated patients undergoing oral surgery. J Oral Maxillofac Surg. 2003 Dec;61(12):1405-9.Pubmed PMID: 14663804.

[10]. Soni A, Narula R, Kumar A, Parmar M, Sahore M, Chandel M. Comparing cyanoacrylate tissue adhesive and conventional subcuticular skin sutures for maxillofacial incisions--a prospective randomized trial considering closure time, wound morbidity, and cosmetic outcome. J Oral Maxillofac Surg. 2013 Dec;71(12):2152.e1-8.Pubmed PMID: 24237777.

[11]. Inal S, Yilmaz N, Nisbet C, Güvenç T. Biochemical and histopathological findings of N-butyl-2-cyanoacrylate in oral surgery: an experimental study. Oral Surg Oral Med Oral Pathol Oral Radiol Endod. 2006 Dec;102(6):e14-7.Pubmed PMID: 17138158.

[12]. Kazzi MG, Silverberg M. Pediatric tongue laceration repair using 2-octyl cyanoacrylate (dermabond $\left(^{(}\right)$). J Emerg Med. 2013 Dec;45(6):846-8.Pubmed PMID: 23827167.

[13]. Burić N. Use of N-butyl cyanoacrylate with metacryloxisulfolane (glubran 2) surgical glue for flapless closure of oroantral communication. Implant Dent. 2013 Jun;22(3):238-43.Pubmed PMID: 23442603.

[14]. Setiya S, Halli R, Shah A, Chhabaria G, Singh T. Comparative evaluation of efficacy of tissue glue and sutures after surgical removal of impacted mandibular third molars-A prospective controlled clinical study. J Oral Maxillofac Surg Med Pathol. 2015 Mar 1;27(2):183-8.

[15]. Waite PD, Cherala S. Surgical outcomes for suture-less surgery in $366 \mathrm{im}-$ pacted third molar patients. J Oral Maxillofac Surg. 2006 Apr;64(4):669-73. Pubmed PMID: 16546647.

[16]. Berkman MD, Cucolo FA, Levin MP, Brunelle LJ. Pulpal response to isobutyl cyanoacrylate in human teeth. J Am Dent Assoc. 1971 Jul;83(1):140-5. Pubmed PMID: 5281165.

[17]. Ellis DA. Comparison of skill suture and N-Butlyl-2-cyanoacrylate on the healing of skin wound. Aust Dent J. 1995 Feb;40(1):43-5.

[18]. Ghoreishian M, Gheisari R, Fayazi M. Tissue adhesive and suturing for closure of the surgical wound after removal of impacted mandibular third molars: a comparative study. Oral Surg Oral Med Oral Pathol Oral Radiol Endod. 2009 Jul;108(1):e14-6.Pubmed PMID: 19464207.

[19]. Mizrahi B, Weldon C, Kohane DS. Tissue adhesives as active implants. InActive implants and scaffolds for tissue regeneration. 2010: 39-56.

[20]. Bhaskar, S.N. and J. Frisch. Use of cyanoacrylate adhesives in dentistry.J Am Dent Assoc.1968. 77(4): 831-837. 